\title{
Prevalence of comorbidities in women with and without breast cancer in Soweto, South Africa: Results from the SABC study
}

\author{
O A Ayeni, ${ }^{1,2} \mathrm{MB}$ ChB, MSc; M Joffe, ${ }^{1,2} \mathrm{PhD}$; H Cubasch, ${ }^{2,3} \mathrm{MB}$ ChB, FCS (SA); S Rinaldi, ${ }^{4} \mathrm{PhD}$; C Taljaard,${ }^{5} \mathrm{PhD}$; E Vorster, ${ }^{5} \mathrm{PhD}$; \\ I Romieu, ${ }^{4,6,7} \mathrm{MD}, \mathrm{MPH}, \mathrm{ScD} ; \mathbf{S}$ A Norris, ${ }^{1,2} \mathrm{PhD}$
}

\author{
${ }^{1}$ SAMRC/Wits Developmental Pathways for Health Research Unit, Department of Paediatrics, Faculty of Health Sciences, \\ University of the Witwatersrand, Johannesburg, South Africa \\ ${ }^{2}$ Non-Communicable Diseases Research Division, Wits Health Consortium (Pty) Ltd, Johannesburg, South Africa \\ ${ }^{3}$ Department of Surgery, Faculty of Health Sciences, University of the Witwatersrand, Johannesburg, South Africa \\ ${ }^{4}$ International Agency for Research on Cancer, Section of Nutrition and Metabolism, Lyon, France \\ ${ }^{5}$ Centre of Excellence for Nutrition, North-West University (Potchefstroom Campus), Potchefstroom, South Africa \\ ${ }^{6}$ Center for Research on Population Health, National Institute of Public Health, Cuernavaca, Morelos, Mexico \\ ${ }^{7}$ Hubert Department of Global Health, Emory University, Atlanta, Ga, USA
}

Corresponding author: O A Ayeni (oluwa.tosinayeni@yahoo.com)

\begin{abstract}
Background. Comorbidities occurring concurrently in breast cancer patients can be burdensome, as they may negatively influence time and stage of presentation.

Objectives. To describe the comorbid health conditions among South African (SA) black women with and without breast cancer and to determine factors associated with advanced-stage presentation of breast cancer.

Methods. A population-based case-control study on breast cancer was conducted in black women in Soweto, SA, the SABC (South Africa Breast Cancer) study. Lifestyle information and blood samples were collected from 399 women with histologically confirmed new cases of invasive primary breast cancer, recruited prior to any therapy, and 399 age- and neighbourhood-matched controls without breast cancer. We compared self-reported metabolic diseases, depression, anthropometric measurements, blood pressure, HIV status and point-of-care lipid and glucose levels between patients with breast cancer and the control group.

Results. In the whole population, the mean (standard deviation) age was 54.6 (12.9) years, the majority (81.2\%) of the participants were overweight or obese, $85.3 \%$ had abdominal adiposity, $61.3 \%$ were hypertensive, $47.1 \%$ had impaired fasting plasma glucose, $8.4 \%$ had elevated total cholesterol, $74.8 \%$ had low high-density lipoprotein and $10.9 \%$ were assessed to be depressed. Ninety-one percent of the whole cohort had at least one metabolic disease. In the breast cancer group, $72.2 \%$ had one or more metabolic diseases only (HIV-negative and no evidence of depression), compared with $64.7 \%$ of the control group. From a multivariate logistic regression adjusted model, higher household socioeconomic status conferred a $19 \%$ reduction in the odds of having advanced-stage breast cancer at diagnosis, while hypertension, dyslipidaemia and HIV were not significantly associated with stage at breast cancer diagnosis in the adjusted model.

Conclusions. A large proportion of women experience several comorbidities, highlighting the need to address the chronic noncommunicable disease epidemic in SA and to co-ordinate multidisciplinary primary-, secondary- and tertiary-level care in the country's complex healthcare system for better outcome.
\end{abstract}

S Afr Med J 2019;109(4):264-271. DOI:10.7196/SAMJ.2019.v109i4.13465

Globally, 41 million people die from non-communicable diseases (NCDs) each year, with $>85 \%$ of deaths occurring in low- and middle-income countries (LMICs), including South Africa (SA). ${ }^{[1]}$ In SA, 39\% of total deaths in 2010 were due to NCDs, with the number of deaths similar to deaths from the combination of HIV and tuberculosis. ${ }^{[2]}$ It is projected that in LMICs the number of deaths from NCDs will be five times higher than the number of deaths from communicable diseases by the year 2030. ${ }^{[3]}$ Most deaths occur in the productive years, compromising the developmental goals defined by the World Health Organization (WHO), which include economic stability, poverty reduction and health equity. ${ }^{[4]}$ The major NCD burden in LMICs is made up of hypertension, cardiovascular diseases, chronic lung diseases, type 2 diabetes, cancer and depression, all of which increase with age. ${ }^{[5]}$ Risk factors such as alcohol consumption, smoking, dietary factors, lack of exercise and excess weight are responsible for a large share of the global disease burden, mediated directly or through conditions such as increased weight/body mass index (BMI), high blood pressure (BP), and elevated cholesterol and blood glucose levels. ${ }^{[6]}$ It is worrisome that in SA this rapidly increasing NCD burden is occurring at the same time as the large number of HIV-positive individuals well managed on antiretroviral treatment is ageing. ${ }^{[7,8]}$

Cancer is one of the major causes of morbidity and mortality globally, with an estimated 14.9 million incident cases and $~ 8.2$ million cancer deaths in 2013 making cancer among the leading causes of death globally. ${ }^{[9]}$ According to the WHO, cancer is the second leading cause of NCD deaths, accounting for $21 \%$ of all NCD deaths. ${ }^{[10]}$ Breast cancer remains the most common cancer among women worldwide and is a major contributor to women's cancer deaths. In LMICs the mortality-to-incidence ratios are comparatively high, mainly owing to advanced stage at diagnosis and suboptimal management. ${ }^{[1]}$ Countries in sub-Saharan Africa, including SA, have 
yet to identify cancer as a priority, allocating limited resources mainly to HIV, tuberculosis and other infectious disease management, ${ }^{[12-17]}$ although the burden of cancer and NCDs in this region is increasing rapidly. ${ }^{[18]}$

Existing lifestyle risk factors and the metabolic syndrome (high blood glucose, high BP, abnormal cholesterol levels and excess fat around the waist) have been associated with increased breast cancer risk, especially in postmenopausal women. ${ }^{[19-22]}$ Studies in LMICs have shown that the prevalence of the metabolic syndrome in breast cancer patients can be as high as $40 \% .{ }^{[21]}$ It has also been reported that about a third of women with breast cancer are likely to experience psychological distress. ${ }^{[23]}$ Studies have shown that the prevalence of anxiety and depression ranges from $1.5 \%$ to $50 \%$ among women with breast cancer, depending on definitions and methods of assessment of psychological disorders. ${ }^{[24,25]}$

There have been conflicting reports on the association of education with breast cancer. Older studies have shown that women with higher education are at an increased risk of developing breast cancer compared with those with low education. ${ }^{[26-28]}$ However, studies conducted in LMICs have reported the reverse. ${ }^{[29,30]}$

Studies have shown that stage at cancer diagnosis is affected by other health conditions, but the direction and magnitude of this effect are highly inconsistent. ${ }^{[31]}$ Several competing mechanisms such as the surveillance hypothesis, psychological hypothesis, competingdemand hypothesis and death-from-other-cause hypothesis may affect stage at diagnosis. ${ }^{[32]}$

The interplay between metabolic diseases, depression, HIV and breast cancer influences cancer treatment decisions and patients' tolerance of and adherence to treatment. ${ }^{[3,34]}$ Furthermore, the presence of metabolic diseases, depression and HIV has also been reported to negatively influence survival in breast cancer patients. ${ }^{[34-37]}$ Metabolic diseases are largely preventable by eliminating risk factors such as harmful alcohol use, tobacco use, physical inactivity and an unhealthy diet. Better understanding of the prevalence of metabolic diseases, depression and HIV in SA populations is needed to improve health policies and service integration. ${ }^{[38]}$

\section{Objectives}

We conducted a population-based case-control study primarily to describe and compare the burden of metabolic diseases, HIV infection and depression in women with and without breast cancer. However, because the covariates analysed could possibly be associated with stage at breast cancer diagnosis, we analysed these covariates further to determine their effect on stage at diagnosis. The objectives of this study were to describe and compare the burden of metabolic diseases, depression and HIV among women newly diagnosed with invasive breast cancer at Chris Hani Baragwanath Academic Hospital (CHBAH), Soweto, SA, with that in age- and residential neighbourhood-matched controls, and to determine factors associated with advanced-stage breast cancer diagnosis.

\section{Methods}

\section{Study design and setting}

The SABC (South Africa Breast Cancer) study is a population-based case-control study set up in Soweto, home to a high-density urban population, to study the aetiology of breast cancer in SA black women. The SABC study is co-ordinated by the International Agency for Research on Cancer in collaboration with the University of the Witwatersrand, CHBAH, North-West University and the University of Southampton.
Women were recruited at the Breast Unit of CHBAH between December 2014 and June 2017. CHBAH is the largest public hospital in SA with $>90 \%$ of patients being black, and it boasts an infrastructure with pathology laboratory services and professional skills that are not easily available in other African settings. Approximately $85 \%$ of patients presenting to $\mathrm{CHBAH}$ are referred from public sector primary- and secondary-care facilities within a $30-60 \mathrm{~km}$ radius, and the rest are either self-referred or referred from private general practitioners. Controls were recruited from the same communities as the cases.

\section{Recruitment of cases and controls Eligibility criteria}

Cases. Women aged $\geq 18$ years with histologically confirmed newly diagnosed breast cancer who provided written consent and met all the inclusion and exclusion criteria were enrolled. Exclusion criteria were pregnancy or breastfeeding, chronic renal disease, a previous cancer diagnosis or inability to answer questions.

Controls. Women aged $\geq 18$ years who matched the cases for age ( \pm 5 years) and area of residence were selected from the Soweto population. Controls were recruited by community volunteers at churches and community centres.

For all subjects, fasting blood samples were collected prior to the start of any treatment (for cases), fractionated into serum, plasma, red blood cells and buffy coats, and stored at $-80^{\circ} \mathrm{C}$. At the same time, spot urine samples were collected from all subjects, aliquoted and stored at $-80^{\circ} \mathrm{C}$.

\section{Procedures}

\section{Interviews}

Investigators and trained study staff conducted face-to-face interviews. We collected detailed information on socioeconomic status (SES) during infancy and early childhood, health and reproductive history (number of births, age at each birth, age at menarche, and duration of breastfeeding for each birth), history of benign breast disease, use of exogenous hormones, smoking habits, alcohol intake, maximum attained body weight, body silhouette at different ages, physical activity (household and recreational) and hours per day spent sedentary (e.g. watching television), diet, occupation, environmental exposures, ethnicity, and family history of cancer. In particular, self-reported demographics, comorbidities (hypertension, diabetes, cardiovascular disease, tuberculosis, hypercholesterolaemia and depression) and socioeconomic indicators (education level, household socioeconomic score determined from motor vehicle ownership and household possessions (refrigerator, microwave, cell phone and landline telephone, washing machine, bed, cooking facilities), with the score calculated as described in a footnote to Table 1) were collected. The Patient Health Questionnaire-9 (PHQ-9) was used to assess depression and other major depressive symptoms. Its validity has been tested in studies in SA and a similar study in Mexican women. ${ }^{[39-41]}$ Only seven of the nine questions from the PHQ were used. The two questions 'Feeling down, depressed or hopeless' and 'Moving or speaking so slowly that other people could have noticed' were omitted because they did not perform well on testretest reliability assessments. ${ }^{[41]}$

\section{Anthropometric data and other measurements}

Body weight, standing and sitting height, and waist and hip circumferences were measured. Pulse and BP were measured according to the American Heart Association recommendations. ${ }^{[2]}$ Participants were seated, and three consecutive readings were taken. 
Table 1. Sociodemographic profile and disease risk in women from the SABC study with and without breast cancer

\begin{tabular}{|c|c|c|c|c|}
\hline \multirow[b]{2}{*}{ Variables } & \multirow[b]{2}{*}{ Total $(N=798)$} & \multicolumn{2}{|c|}{ Participants } & \multirow[b]{2}{*}{$p$-value } \\
\hline & & $\begin{array}{l}\text { Breast cancer } \\
(N=399)\end{array}$ & Controls $(N=399)$ & \\
\hline Age (years), mean (SD) & $54.6(12.9)$ & $54.6(12.8)$ & $54.7(12.9)$ & 0.939 \\
\hline \multicolumn{5}{|l|}{ Level of education, $n$ (\%) } \\
\hline Completion of primary education and below & $167(20.9)$ & $97(24.3)$ & $70(17.5)$ & \multirow[t]{3}{*}{$0.023^{*+}$} \\
\hline Completion of secondary education & $617(77.3)$ & $298(74.7)$ & $319(80.0)$ & \\
\hline Some tertiary education & $14(1.8)$ & $4(1.0)$ & $10(2.5)$ & \\
\hline Household SES (assets score, $0-8^{\ddagger}$ ), mean (SD) & $5.4(1.3)$ & $5.4(1.3)$ & $5.5(1.3)$ & 0.182 \\
\hline \multicolumn{5}{|l|}{ BMI $\left(\mathrm{kg} / \mathrm{m}^{2}\right), n(\%)$} \\
\hline Underweight ${ }^{\S}$ and normal $(<24.9)$ & $150(18.8)$ & $82(20.5)$ & $68(17.0)$ & \multirow[t]{4}{*}{0.649} \\
\hline Overweight $(25.0-29.9)$ & $192(24.1)$ & $93(23.3)$ & $99(24.8)$ & \\
\hline Obese $(30.0-39.9)$ & $215(26.9)$ & $105(26.3)$ & $110(27.6)$ & \\
\hline Morbidly obese ( $\geq 40$ ) & $241(30.2)$ & $119(29.8)$ & $122(30.6)$ & \\
\hline Waist circumference $(\mathrm{cm})$, mean $(\mathrm{SD})$ & $94.6(13.8)$ & $93.4(13.8)$ & $95.9(13.7)$ & $0.009^{*}$ \\
\hline \multicolumn{5}{|c|}{ Abdominal adiposity (waist circumference in $\mathrm{cm}$ ), $n$ (\%) } \\
\hline$<80$ & $117(14.7)$ & $64(16.0)$ & $53(13.3)$ & \multirow[t]{2}{*}{0.271} \\
\hline$\geq 80$ & $681(85.3)$ & $335(84.0)$ & $346(86.7)$ & \\
\hline \multicolumn{5}{|l|}{ Dyslipidaemia (TC and HDL in $\mathrm{mmol} / \mathrm{L}$ ), $n(\%)$} \\
\hline $\mathrm{TC} \leq 6.21$ & $731(91.6)$ & $368(92.2)$ & $363(91.0)$ & \multirow[t]{2}{*}{0.523} \\
\hline $\mathrm{TC}>6.21$ & $67(8.4)$ & $31(7.8)$ & $36(9.0)$ & \\
\hline $\mathrm{HDL} \leq 1.3$ & $597(74.8)$ & $310(77.7)$ & $287(71.9)$ & \multirow[t]{2}{*}{0.061} \\
\hline $\mathrm{HDL}>1.3$ & $201(25.2)$ & $89(22.3)$ & $112(28.1)$ & \\
\hline \multicolumn{5}{|c|}{$\begin{array}{l}\text { Hypertension (BP reading alone in } \mathrm{mmHg} \text {, patients hypertensive } \\
\text { on medications excluded), } n(\%)\end{array}$} \\
\hline Normal BP $(<120 /<80)$ & $167(36.5)$ & $84(36.4)$ & $83(36.7)$ & \multirow[t]{4}{*}{0.323} \\
\hline Category $1(120-139 / 80-89)$ & $142(31.1)$ & $79(34.2)$ & $63(27.9)$ & \\
\hline Category $2(140-159 / 90-99)$ & $99(21.7)$ & $43(18.6)$ & $56(24.8)$ & \\
\hline Category $3(\geq 160 / \geq 100)$ & $49(10.7)$ & $25(10.8)$ & $24(10.6)$ & \\
\hline \multicolumn{5}{|c|}{ Hypertension (using either BP reading or medication use), $n$ (\%) } \\
\hline No & $309(38.7)$ & $163(40.8)$ & $146(36.6)$ & \multirow[t]{2}{*}{0.217} \\
\hline Yes & $489(61.3)$ & $236(59.2)$ & $253(63.4)$ & \\
\hline \multicolumn{5}{|l|}{ Fasting glucose (mmol/L), $n(\%)$} \\
\hline$\leq 5.5$ & $422(52.9)$ & $212(53.4)$ & $210(52.6)$ & \multirow[t]{3}{*}{0.828} \\
\hline$>5.5$ & $376(47.1)$ & $185(46.6)$ & $189(47.4)$ & \\
\hline Missing & 2 & 2 & 0 & \\
\hline \multicolumn{5}{|c|}{$\begin{array}{l}\text { Risk of depression (using either PHQ-9 score or self-reported } \\
\text { depression), } n \text { (\%) }\end{array}$} \\
\hline No & $711(89.1)$ & $364(91.2)$ & $347(87.0)$ & \multirow[t]{2}{*}{0.053} \\
\hline Yes & $87(10.9)$ & $35(8.8)$ & $52(13.0)$ & \\
\hline \multicolumn{5}{|l|}{ HIV status, $n(\%)$} \\
\hline Negative & $642(80.5)$ & $333(83.5)$ & $309(77.4)$ & \multirow[t]{2}{*}{$0.032^{*}$} \\
\hline Positive & $156(19.5)$ & $66(16.5)$ & $90(22.6)$ & \\
\hline \multicolumn{5}{|c|}{ 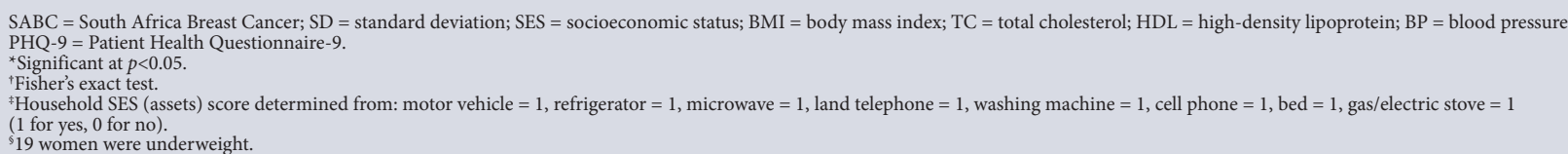 } \\
\hline
\end{tabular}

\section{Blood measurements}

Fasting plasma glucose and lipids (total cholesterol (TC) and highdensity lipoprotein (HDL)) were measured enzymatically with a glucose oxidase method and cholesterol oxidase method, respectively, using the RX Daytona Plus (Randox, UK) automated clinical chemistry analyser method. The coefficient of variation for the laboratory technician was $<2 \%$ for the assays. Cases and controls were measured in the same batch. HIV status was measured by either the HIV 1-2 rapid test (Alere Inc., USA) for the controls or an enzyme-linked immunosorbent assay
(ELISA) through the National Health Laboratory Service for the cases, because the cases were enrolled through the clinic.

\section{Comorbidity measurements and classifications}

The main comorbidities measured were obesity, hyperlipidaemia, hyperglycaemia, hypertension, depression and HIV infection. Obesity was determined by calculating the BMI from the height and weight using the WHO obesity cut-offs. A BMI of $<18.5 \mathrm{~kg} / \mathrm{m}^{2}$ was categorised as underweight, $18.5-24.9 \mathrm{~kg} / \mathrm{m}^{2}$ as normal, $25-29.9 \mathrm{~kg} / \mathrm{m}^{2}$ as 
overweight, $30-39.9 \mathrm{~kg} / \mathrm{m}^{2}$ as obese, and $\geq 40 \mathrm{~kg} / \mathrm{m}^{2}$ as morbidly obese. ${ }^{[43]}$ Dyslipidaemia was defined as a TC level of $>6.21 \mathrm{mmol} / \mathrm{L}$ or an HDL level of $<1.19 \mathrm{mmol} / \mathrm{L}$, while a fasting glucose level of $>5.5 \mathrm{mmol} / \mathrm{L}$ was considered to indicate impaired fasting glucose. ${ }^{[4,45]}$ $\mathrm{BP}$ was calculated using the average between the second and third $\mathrm{BP}$ readings. Hypertension was defined using BP readings alone and categorised as normal blood pressure (systolic $<120 \mathrm{mmHg}$ and diastolic $<80 \mathrm{mmHg}$ ), category 1 (systolic $120-139 \mathrm{mmHg}$ or diastolic $80-89 \mathrm{mmHg}$ ), category 2 (systolic $140-159 \mathrm{mmHg}$ or diastolic 90 - $99 \mathrm{mmHg}$ ) or category 3 (systolic $\geq 160 \mathrm{mmHg}$ or diastolic $\geq 100 \mathrm{mmHg}$ ). ${ }^{[46]}$ It was further defined as 'No' or 'Yes' (mean systolic BP of $\geq 140 \mathrm{mmHg}$ or mean diastolic BP $\geq 90 \mathrm{mmHg}$, or normal BP with self-reported hypertensive medication use).

\section{Outcome measurement}

The primary outcome measurement was stage at breast cancer presentation to the CHBAH Breast Unit (early stage I and II v. advanced stage III and IV), which was extracted from the Breast Unit database. Stage was assessed clinically at diagnosis. It was primarily coded according to the tumour-node-metastasis (TNM) classification and then converted to Manchester staging.

\section{Statistical analysis}

Differences in demographics, socioeconomic factors, metabolic diseases, depression and HIV between the breast cancer and control groups were described and reported using Pearson's $\chi^{2}$ and Fisher's exact tests for categorical variables. Means and standard deviations (SDs) were computed for continuous variables using Student's $t$-test to report differences between groups. Frequencies of metabolic diseases in the cohort were analysed and reported, and frequencies of metabolic diseases, depression and HIV in breast cancer patients were also analysed with stage at breast cancer diagnosis as the outcome variable. To examine associations with advanced-stage breast cancer, we used multivariable logistic regression models. Variables for which $p$-values were $<0.1$ in bivariate analysis were included in our multivariate models. Odds ratios (ORs) were examined in three models in our multivariate analysis, with $r^{2}$ values (coefficient of determination) reported as explained variation. We added in a stepwise fashion sociodemographic factors (age and household SES), dyslipidaemia, hypertension and HIV to examine the association between these factors and advanced presentation of breast cancer. Analysis was performed using Stata version 14 (StataCorp, USA).

\section{Ethical considerations}

The study was approved by the University of the Witwatersrand Human Research Ethics Committee (ref. no. Ml40980) and the International Agency for Research on Cancer Ethics Committee (ref. no. IEC 12-38).

\section{Results}

A total of 798 women (399 cases and 399 controls) were correctly matched for both neighbourhood and age to within 5 years. In the first year of recruitment, controls were enrolled independently of case matching in accordance with a predictive recruitment algorithm developed from analysis of patients enrolled in a previous study. ${ }^{[47]}$ The characteristics of the cohort are summarised in Table 1. The overall mean age (SD) was 54.6 (12.9) years. Educational level, HIV status and waist circumference differed significantly between the two groups. Women in the control group were more likely than the breast cancer patients to have schooling beyond primary education $(p=0.023)$. Over a fifth $(22.6 \%)$ of the women in the control group were HIV-positive, while the figure for the breast cancer group was $16.5 \%(p=0.032)$. The mean (SD) waist circumference in the control group was $95.9(13.7) \mathrm{cm}$ while that in the breast cancer group was $93.4(13.7) \mathrm{cm}(p=0.009)$. There were no significant differences in household SES, nutritional status (BMI), level of hypertension, dyslipidaemia, fasting plasma glucose or assessment of depression between the two groups. In the total cohort, the majority $(81.2 \%)$ of the participants were overweight or obese, $85.3 \%(n=681)$ had abdominal adiposity, $8.4 \%(n=102)$ had elevated TC, $74.8 \%(n=597)$ had low HDL, 47.1\% (376) had impaired fasting plasma glucose, $61.3 \%(n=489)$ were hypertensive, with $43.2 \%(n=341)$ on treatment, and $10.9 \%(n=87)$ were assessed to be depressed (Table 1 ).

In determining the number of metabolic diseases reported in the whole cohort, only $9 \%(n=72)$ of the women had no metabolic disease; $24.1 \%(n=192)$ had one metabolic disease, $38.1 \%(n=304)$ had two metabolic diseases, $24.7 \%(n=197)$ had three metabolic diseases and $4.1 \%(n=33)$ had four metabolic diseases (Table 2). There were no significant differences in the number of metabolic diseases between the cases and their controls $(p=0.285)$.

When combining at least one metabolic disease, depression and HIV, $2.9 \%(n=23)$ of the women presented with these three diseases in the whole cohort, and this proportion was almost doubled in the control group $(3.8 \%, n=15)$ compared with the breast cancer group $(2.0 \%, n=8)$. The majority $(72.2 \%, n=285)$ of the women in the breast cancer group and $64.7 \%(n=257)$ of those in the control group presented with metabolic diseases alone (HIV-negative and no evidence of depression).

Women with no metabolic disease, depression or HIV comprised $5.8 \%(n=23)$ and $4.0 \%(n=16)$ of the breast cancer group and the control group, respectively. The distribution of metabolic diseases, depression and HIV was significantly different between the breast cancer and control groups ( $p=0.036$ ) (Table 3).

In bivariate analysis, among women from the breast cancer group (Table 4) there was a $21 \%$ reduction in the odds of presenting with advanced-stage breast cancer for every unit increase in household

Table 2. Frequency of metabolic diseases* in women from the SABC study, overall and by case/control status

\begin{tabular}{|c|c|c|c|c|}
\hline Metabolic diseases, $n$ & Total $(N=798), n(\%)$ & Breast cancer $(N=399), n(\%)$ & Controls $(N=399), n(\%)$ & $p$-value \\
\hline 0 & $72(9.0)$ & $42(10.5)$ & $30(7.5)$ & 0.285 \\
\hline 1 & $192(24.1)$ & $101(25.3)$ & $91(22.8)$ & \\
\hline 2 & $304(38.1)$ & $139(34.9)$ & $165(41.3)$ & \\
\hline 3 & $197(24.7)$ & $99(24.8)$ & $98(24.6)$ & \\
\hline 4 & $33(4.1)$ & $18(4.5)$ & $15(3.8)$ & \\
\hline Total & $798(100)$ & $399(100)$ & $399(100)$ & \\
\hline
\end{tabular}


Table 3. Frequency of at least one metabolic disease, ${ }^{\star}$ depression and HIV in women from the SABC study, overall and by case/control status

\begin{tabular}{|c|c|c|c|c|}
\hline At least one MD, D, HIV & Total $(N=798), n(\%)$ & Breast cancer $(N=399), n(\%)$ & Controls $(N=399), n(\%)$ & $p$-value \\
\hline $\mathrm{MD}+, \mathrm{D}-, \mathrm{HIV}-$ & $542(68.4)$ & $285(72.2)$ & $257(64.7)$ & 0.036 \\
\hline $\mathrm{MD}+, \mathrm{D}-, \mathrm{HIV}+$ & $103(13.0)$ & $41(10.4)$ & $62(15.6)$ & \\
\hline $\mathrm{MD}+, \mathrm{D}+, \mathrm{HIV}-$ & $58(7.3)$ & $23(5.8)$ & $35(8.8)$ & \\
\hline MD-, D-, HIV+ & $27(3.4)$ & $15(3.8)$ & $12(3.0)$ & \\
\hline $\mathrm{MD}+, \mathrm{D}+, \mathrm{HIV}+$ & $23(2.9)$ & $8(2.0)$ & $15(3.8)$ & \\
\hline MD-, D-, HIV- & $39(4.9)$ & $23(5.8)$ & $16(4.0)$ & \\
\hline Total & $792(100)$ & $395(100)$ & $397(100)$ & \\
\hline Not shown ${ }^{\dagger}$ & 6 & 4 & 2 & \\
\hline
\end{tabular}

Table 4. Bivariate analysis of variables associated with advanced-stage presentation (stages III and IV) among women diagnosed with breast cancer at the Chris Hani Baragwanath Academic Hospital Breast Clinic in Soweto, South Africa

\begin{tabular}{|c|c|c|}
\hline Variables & $\begin{array}{l}\text { Bivariate analysis } \\
\text { OR }(95 \% \mathrm{CI})\end{array}$ & $p$-value \\
\hline Age (years) & $0.99(0.97-1.00)$ & 0.162 \\
\hline \multicolumn{3}{|l|}{ Level of education } \\
\hline Completion of primary education and below & $3.47(0.35-34.51)$ & 0.384 \\
\hline Completion of secondary education & $2.77(0.28-26.90)$ & \\
\hline Some tertiary education & Reference & \\
\hline Household SES (asset score) & $0.79(0.67-0.92)$ & $0.002^{*}$ \\
\hline \multicolumn{3}{|l|}{ BMI $\left(\mathrm{kg} / \mathrm{m}^{2}\right)$} \\
\hline Underweight and normal $(<24.9)$ & Reference & 0.343 \\
\hline Overweight (25.0 - 29.9) & $0.80(0.44-1.45)$ & \\
\hline Obese $(30.0-39.9)$ & $0.59(0.33-1.05)$ & \\
\hline Morbidly obese $(\geq 40)$ & $0.74(0.42-1.31)$ & \\
\hline Waist circumference & $0.99(0.98-1.00)$ & 0.167 \\
\hline \multicolumn{3}{|l|}{ Abdominal adiposity (waist circumference in $\mathrm{cm}$ ) } \\
\hline$<80$ & $1.41(0.82-2.41)$ & 0.212 \\
\hline$\geq 80$ & Reference & \\
\hline \multicolumn{3}{|l|}{ Dyslipidaemia (TC and HDL in $\mathrm{mmol} / \mathrm{L}$ ) } \\
\hline $\mathrm{TC} \leq 6.21$ & $2.53(1.13-5.63)$ & $0.018^{*}$ \\
\hline $\mathrm{TC}>6.21$ & Reference & \\
\hline $\mathrm{HDL} \leq 1.3$ & $1.77(1.09-2.87)$ & $0.019^{*}$ \\
\hline $\mathrm{HDL}>1.3$ & Reference & \\
\hline \multicolumn{3}{|c|}{$\begin{array}{l}\text { Hypertension (BP reading alone in } \mathrm{mmHg} \text {, patients hypertensive on } \\
\text { medications excluded) }\end{array}$} \\
\hline Normal $(<120 /<80)$ & Reference & 0.516 \\
\hline Category $1(120-139 / 80-89)$ & $1.15(0.62-2.14)$ & \\
\hline Category $2(140-159 / 90-99)$ & $0.65(0.31-1.37)$ & \\
\hline Category $3(\geq 160 / \geq 100)$ & $0.89(0.37-2.19)$ & \\
\hline \multicolumn{3}{|c|}{ Hypertension (using either BP reading or medication use) } \\
\hline No & $1.64(1.09-2.46)$ & $0.015^{*}$ \\
\hline Yes & Reference & \\
\hline \multicolumn{3}{|l|}{ Impaired fasting glucose $(\mathrm{mmol} / \mathrm{L})$} \\
\hline$\leq 5.5$ & Reference & 0.217 \\
\hline$>5.5$ & $1.28(0.86-1.90)$ & \\
\hline \multicolumn{3}{|c|}{ Risk of depression (using either PHQ-9 score or self-reported depression) } \\
\hline No & $1.31(0.65-2.66)$ & 0.437 \\
\hline Yes & Reference & \\
\hline \multicolumn{3}{|l|}{ HIV status } \\
\hline Negative & Reference & $0.041^{*}$ \\
\hline Positive & $1.75(1.01-2.99)$ & \\
\hline
\end{tabular}


SES asset score (OR 0.79, 95\% confidence interval (CI) 0.67 - 0.92). Women with a TC level $\leq 6.21 \mathrm{mmol} / \mathrm{L}$ and an HDL level $\leq 1.3 \mathrm{mmol} / \mathrm{L}$ had a higher risk of advanced-stage disease (OR 2.53, 95\% CI 1.13 5.63 and OR 1.77, 95\% CI $1.09-2.87$, respectively). Women who were HIV-positive but not hypertensive were also more likely to present with advanced-stage disease (OR 1.64, 95\% CI 1.09- 2.46 and OR 1.75, 95\% CI $1.01-2.99$, respectively). Variables significant in the bivariate analysis were further explored in individual and combined logistic regression models controlling for age (Table 5).

Sociodemographic factors (model 1) independently explained $2.9 \%$ of the variance, and household SES was shown to partially influence the likelihood of advanced stage at diagnosis. Comorbid factors (model 2) explained 3.3\% of the variance, with patients with no dyslipidaemia and patients with no hypertension having greater odds of advanced-stage presentation. In the final model with all factors included (model 3), $4.9 \%$ of the variance was explained. The associations of advanced-stage breast cancer with household SES were slightly attenuated on adjustment (OR $0.81,95 \%$ CI 0.69 - 0.95), whereas associations with hypertension, dyslipidaemia and HIV were no longer significant in mutually adjusted models (Table 5).

\section{Discussion}

We found that there was a high burden of metabolic diseases, depression and HIV in women with and without breast cancer in Soweto. About two-thirds of the whole cohort had two or more metabolic diseases and $10.2 \%$ had at least one metabolic disease and depression. The prevalence of metabolic diseases and depression was comparable in women with breast cancer and those without.

Women with breast cancer had lower levels of education compared with their controls. There was a significant difference in waist circumference and HIV status between the two groups, while levels of obesity, hyperlipidaemia, hypertension, hyperglycaemia and depression were similar. The combination of at least one metabolic disease, depression and HIV differed between the breast cancer group and the control group. A higher household socioeconomic asset score was protective against advanced-stage breast cancer at presentation, while hypertension, dyslipidaemia and HIV had no significant influence on stage at presentation.

The study demonstrated that women with breast cancer were significantly less educated than their controls, supporting literature reports that showed less-educated women and women with low SES to be at increased risk of breast cancer. ${ }^{[2,30]}$ The increased risk of breast cancer in less educated women is partly due to changes in reproductive factors and lifestyle modification. We reported a high prevalence of comorbidity among Soweto women in general, corroborating findings from previous studies in SA from various settings. ${ }^{[4,49]}$ About one-fifth of our whole cohort were HIV-positive, while almost $14 \%$ of breast cancer patients with at least one metabolic disease and depression were also positive for HIV. This finding further supports the fact that our population is carrying a double burden involving an epidemiological overlap of NCDs and infectious diseases.

Studies have reported an association between metabolic diseases and risk of breast cancer, especially in postmenopausal women. ${ }^{[2,50]}$ There was no significant difference in our study with regard to individual metabolic disease components (obesity, dyslipidaemia, hypertension and hyperglycaemia) or in the number of metabolic diseases with which women with and without breast cancer presented; however, the proportion of women presenting with metabolic diseases was so high in both groups that significant differences were difficult to detect. Several factors, such as physical activity, dietary intake, smoking and alcohol intake, could explain the high prevalence of metabolic diseases in our study, and these lifestyle behaviours will be the focus of a future article.

Women with higher SES tended to present with early-stage breast cancer disease. It has been reported that intention to seek medical care is not entirely dependent on education and SES but on complex personal and social factors and previous healthcare-seeking habits. ${ }^{[51]}$ Appropriate targeted interventions to address inequalities evident in stage at breast cancer diagnosis may help in improving stage at diagnosis.

The cost of care of breast cancer patients with metabolic diseases, depression and HIV places a big burden on the limited

Table 5. Multiple logistic regression models of factors influencing advanced-stage presentation (stages III and IV) among women diagnosed with breast cancer at the Chris Hani Baragwanath Academic Hospital Breast Clinic in Soweto, South Africa

\begin{tabular}{|c|c|c|c|c|}
\hline Variables & $\begin{array}{l}\text { Bivariate analysis } \\
\text { OR }(95 \% \mathrm{CI})\end{array}$ & $\begin{array}{l}\text { Model 1, } \\
\text { sociodemographic } \\
\text { OR }(95 \% \mathrm{CI})\end{array}$ & $\begin{array}{l}\text { Model 2, } \\
\text { comorbidities } \\
\text { OR }(95 \% \mathrm{CI}) \\
\end{array}$ & $\begin{array}{l}\text { Model 3, } \\
\text { sociodemographic + } \\
\text { comorbidities } \\
\text { OR }(95 \% \mathrm{CI}) \\
\end{array}$ \\
\hline \multicolumn{5}{|l|}{ Sociodemographic } \\
\hline Age in years & $0.99(0.97-1.00)$ & $0.99(0.97-1.00)$ & & $0.99(0.98-1.02)$ \\
\hline Household socioeconomic status (asset score) & $0.79(0.67-0.92)^{*}$ & $0.79(0.67-0.92)^{*}$ & & $0.81(0.69-0.95)^{*}$ \\
\hline \multicolumn{5}{|l|}{ Comorbidities } \\
\hline \multicolumn{5}{|l|}{ Dyslipidaemia (TC in $\mathrm{mmol} / \mathrm{L}$ ) } \\
\hline$\leq 6.21$ & $2.53(1.13-5.63)^{*}$ & & $2.46(1.10-5.54)^{*}$ & $2.18(0.96-4.96)$ \\
\hline$>6.21$ & Reference & & Reference & Reference \\
\hline \multicolumn{5}{|l|}{$\begin{array}{l}\text { Hypertension (using either BP reading or } \\
\text { medication use) }\end{array}$} \\
\hline No & $1.64(1.09-2.46)^{*}$ & & $1.56(1.04-2.35)^{*}$ & $1.50(0.96-2.35)$ \\
\hline Yes & Reference & & Reference & Reference \\
\hline \multicolumn{5}{|l|}{ HIV status } \\
\hline Negative & Reference & & Reference & Reference \\
\hline Positive & $1.75(1.01-2.99)^{*}$ & & $1.60(0.93-2.77)$ & $1.44(0.80-2.57)$ \\
\hline$r^{2}$ & & $0.0286^{*}$ & $0.0335^{*}$ & $0.0486^{*}$ \\
\hline
\end{tabular}


healthcare resources in SA public hospitals. Controlling cost of care and significant patient out-of-pocket costs should be of great concern among public and private managers and policymakers. The integrated chronic disease management (ICDM) model was introduced as a response to the dual burden of HIV/AIDS and NCDs in SA. However, the aim for which the ICDM model was initiated, i.e. to use the HIV programme as leverage for scaling up services for NCDs, is yet to be achieved. ${ }^{[52]}$ The majority of patients experiencing multiple comorbidities visit healthcare facilities frequently. Navigation and co-ordination of care in these patients can be very difficult, and ultimately they are vulnerable to suboptimal quality of care. Our results highlight the necessity for health system integration of services and continuity of care. ${ }^{[53]}$ The management of breast cancer patients also burdened with metabolic diseases, depression and HIV may result in further fragmentation of care, as cancer treatment is complex and multidisciplinary in nature. It is therefore essential for patient management to extend beyond the cancer domain and include the high burden of other communicable and non-communicable diseases. Co-ordination and integration of care for cancer and other comorbid conditions is fundamental to cost-effective healthcare delivery for patients and health systems alike, as previously identified. ${ }^{[5,55]}$ Shared hospital appointments, community-based cancer care and collaboration with primary healthcare services may all be helpful in improving co-ordination of care for breast cancer patients and may improve survival outcomes in these patients.

Poor quality of life and survival among women with breast cancer may be exacerbated by multiple comorbidities. ${ }^{[56]}$ Other factors that may adversely affect outcome include large out-of-pocket expenses such as transport costs and loss of wages and employment that may result in poor adherence to multiple treatments and adverse drug interactions that may affect cancer treatment efficacy and tolerance. Breast cancer patients with comorbidities are more likely than those without to experience adverse outcomes as a result of noncompletion of radiation therapy and are less likely to initiate and complete chemotherapy. ${ }^{[57,58]}$

\section{Study limitations}

The limitations to this study include the fact that it was conducted in Soweto, which means that our findings may not be generalisable to the whole population of SA. Some bias is possible in our recruitment and exposure assessment, but our participation rate was high $(91.3 \%)$ and women were not aware of our research hypothesis. Any misclassification is therefore probably random. Simultaneous testing of several hypotheses was carried out in our analysis to assess differences in sociodemographic factors and metabolic diseases, depression and HIV across stage at breast cancer presentation. This could reduce the significance value to very precise levels and increases the chances of a false-negative error (type 2 error); ${ }^{[59]}$ however, our focus was more on the actual effect size than the level of significance, and our analysis was focused on a single primary endpoint. Despite these limitations, knowledge gained from this study on the prevalence of metabolic diseases, depression and HIV in women from Soweto with and without breast cancer and our finding on the importance of the household socioeconomic asset score in relation to stage at breast cancer diagnosis highlight the need for better community awareness and screening for metabolic diseases, depression, HIV and other chronic disease, for further research on treatment compliance in patients with breast cancer, treatment tolerance and efficacy and survival outcomes, and for integration of care for multi-comorbidities.

\section{Conclusions}

Many SA women with breast cancer from socioeconomically disadvantaged communities are burdened with metabolic diseases, depression and HIV. There is a need for research on treatment efficacy and tolerance, and co-ordination of care for easier navigation in SA's complex healthcare system.

Declaration. This publication was a requirement for $\mathrm{OA}$ 's $\mathrm{PhD}$ degree. Acknowledgements. We thank the World Cancer Research Fund for their support in this study, the participants who provided the data for the study, and the team at the CHBAH Batho Pele breast clinic and the SAMRC/Wits Developmental Pathways for Health Research Unit, who have served and continue to serve their patients with skill and devotion.

Author contributions. Conceptualisation: OA, MJ, SAN; data curation: OA, MJ, HC; formal analysis: OA, SAN; funding acquisition: MJ, SR, IR; methodology: MJ, SR, EV, SAN; software: OA; writing, original draft: OA; writing, review and editing: OA, MJ, HC, SR, CJ, EV, IR, SAN.

Funding. This work was supported by: (i) the World Cancer Research Fund, (ii) National Institutes of Health grant NIH/R01-CA192627-01 to MJ, Dr Judith S Jacobson (Department of Epidemiology, Mailman School of Public Health, Columbia University, New York, USA) and Dr Alfred I Neugut (Herbert Irving Comprehensive Cancer Center, Department of Medicine and Department of Epidemiology, Mailman School of Public Health, Columbia University), our collaborators from the USA, and Prof. Paul Ruff, head of the Division of Medical Oncology, Department of Medicine, Faculty of Health Sciences, University of the Witwatersrand, also our collaborator in the breast cancer unit; (iii) the South African Medical Research Council/University of the Witwatersrand Common Epithelial Cancer Research Centre led by Prof. Ruff; and (iv) the Cancer Association of South Africa grant 'Down-staging and improving survival of breast cancer in South Africa' (HC).

Conflicts of interest. The commercial affiliation to the Wits Health Consortium (Pty) Ltd of authors OA, MJ, HC and SAN does not alter their adherence to $S A M J$ policies on sharing data and materials.

1. World Health Organization. Non Communicable Diseases: Fact sheet updated June 2018. Geneva: WHO, 2018. http://www.who.int/news-room/fact-sheets/detail/noncommunicable-diseases (accessed 10 June 2018).

2. Nojilana B, Bradshaw D, Pillay-Van Wyk V, et al. Persistent burden from non-communicable diseases

in South Africa needs strong action. S Afr Med J 2016;106(5):436-437. https://doi.org/10.7196/ in South Africa needs strong action. S Afr Med J 2016;106(5):436-437. https://doi.org/10.7196/
SAMI.2016.V10615.10776 SA

World Health Organization. The Global Burden of Disease: 2004 Update. Geneva: WHO, 2008. http:/ www.who.int/iris/handle/10665/43942 (accessed 14 May 2018).

4. Beaglehole R, Bonita R, Horton R, et al. Priority actions for the non-communicable disease crisis. Lancet 2011;377(9775):1438-1447. https://doi.org/10.1016/S0140-6736(11)60393-0

5. Daar AS, Singer PA, Persad DL, et al. Grand challenges in chronic non-communicable diseases. Nature 2007;450(7169):494-496. https://doi.org/10.1038/450494a

6. Ezzati M, Lopez AD, Rodgers A, et al. Selected major risk factors and global and regional burden of disease. Lancet 2002;360(9343):1347-1360. https://doi.org/10.1016/S0140-6736(02)11403-6

Mayosi BM, Flisher AJ, Lalloo UG, et al. The burden of non-communicable diseases in South Africa. Lancet 2009;374(9693):934-947. https://doi.org/10.1016/S0140-6736(09)61087-4

Hofman K. Non-communicable diseases in South Africa: A challenge to economic development. S Afr Med J 2014;104(10):647. https://doi.org/10.7196/SAMJ.8727

9. Ferlay J, Soerjomataram I, Dikshit R, et al. Cancer incidence and mortality worldwide: Sources methods and major patterns in GLOBOCAN 2012. Int J Cancer 2015;136(5):E359-E386. https://doi.
mo methods and major pater
org/10.1002/ijc. 29210

10. Stewart B, Wild CP. International Agency for Research on Cancer, World Health Organization. World Stewart B, Wild CP. International Agency for Research on Cancer, World Health Organization. World
Cancer Report 2014. Lyon: IARC, 2014. http://publications.iarc.fr/Non-Series-Publications/WorldCancer-Reports/World-Cancer-Report-2014 (accessed 14 May 2018).

11. Torre LA, Bray F, Siegel RL, Ferlay J, Lortet-Tieulent J, Jemal A. Global cancer statistics, 2012. CA Cancer J Clin 2015;65(2):87-108. https://doi.org/10.3322/caac.21262

12. Edge J, Buccimazza I, Cubasch $H$, Panieri E. The challenges of managing breast cancer in the developing world - a perspective from sub-Saharan Africa. S Afr Med J 2014(5);104:377-379. https:// doi.org/10.7196/SAMJ.8249

13. Farmer P, Frenk J, Knaul FM, et al. Expansion of cancer care and control in countries of low and middle income: A call to action. Lancet 2010;376(9747):1186-1193. https://doi.org/10.1016/S01406736(10)61152-X

14. Hanna TP, Kangolle AC. Cancer control in developing countries: Using health data and health services research to measure and improve access, quality and efficiency. BMC Int Health Hum Rights 2010;10(1):24. https://doi.org/10.1186/1472-698X-10-24 
15. Jemal A, Bray F, Forman D, et al. Cancer burden in Africa and opportunities for prevention. Cancer 2012;118(18):4372-4384. https://doi.org/10.1002/cncr.27410

16. Kantelhardt EJ, Hanson C, Albert US, Wacker J. Breast cancer in countries of limited resources. Breast Kantelhardt E], Hanson C, Albert US, Wacker J. Breast cancer in coun (Basel) 2008;3(1):10-16. https://doi.org/10.1159/000114409
Care

17. Levitt NS, Steyn K, Dave J, Bradshaw D. Chronic noncommunicable diseases and HIV-AIDS on a
(B. Levitt NS, Steyn K, Dave J, Bradshaw D. Chronic noncommunicable diseases and HIV-AIDS on a
collision course: Relevance for health care delivery, particularly in low-resource settings - insights collision course: Relevance for health care delivery, particularly in low-resource settings - insights
from South Africa. Am J Clin Nutr 2011;94(6):1690S-1696S. https://doi.org/10.3945/aicn.111.019075 from South Africa. Am J Clin Nutr 2011;94(6):1690S-1696S. https://doi.org/10.3945/ajcn.111.019075
18. Nyirenda MJ. Non-communicable diseases in sub-Saharan Africa: Understanding the drivers of the 18. Nyirenda MJ. Non-communicable diseases in sub-Saharan Africa: Understanding the drivers of the
epidemic to inform intervention strategies. Int Health 2016;8(3):157-158. https://doi.org/10.1093/ epidemic to inform
inthealth/ihw021

19. Bhandari R, Kelley GA, Hartley TA, Rockett IRH. Metabolic syndrome is associated with increased breast cancer risk: A systematic review with meta-analysis. Int J Breast Cancer 2014;2014:189384. https://doi.org/10.1155/2014/189384

20. Gezgen G, Roach EC, Kizilarslanoglu MC, Petekkaya I, Altundag K. Metabolic syndrome and breast cancer: An overview. J BUON 2012;17(2):223-229.

21. Wani B, Aziz SA, Ganaie MA, Mir MH. Metabolic syndrome and breast cancer risk. Indian J Med Paediatr Oncol 2017;38(4):434-439. https://doi.org/10.4103/ijmpo.ijmpo_168_16

22. Agnoli C, Grioni S, Sieri S, et al. Metabolic syndrome and breast cancer risk: A case-cohort study nested in a multicentre Italian cohort. PLoS One 2015:10(6):e0128891. https://doi.org/10.1371/ journal.pone.0128891

23. Knobf MT. Psychosocial responses in breast cancer survivors. Semin Oncol Nurs 2007;23(1):71-83. Knobf MT. Psychosocial responses in breas
https://doi.org/10.1016/.soncn.2006.11.009

24. Massie MJ. Prevalence of depression in patients with cancer. J Natl Cancer Inst Monogr 2004;(32):57 71. https://doi.org/10.1093/jncimonographs/lgh014

25. Zainal NZ, Nik-Jaafar NR, Baharudin A, Sabki ZA, Ng CG. Prevalence of depression in breast cancer survivors: A systematic review of observational studies. Asian Pac J Cancer Prev 2013;14(4):2649-2656. https://doi.org/10.7314/APJCP.2013.14.4.2649

26. Heck KE, Pamuk ER. Explaining the relation between education and postmenopausal breast cancer Am J Epidemiol 1997;145(4):366-372. https://doi.org/10.1093/oxfordjournals.aje.a009114

27. Hussain SK, Altieri A, Sundquist J, Hemminki K. Influence of education level on breast cancer risk and survival in Sweden between 1990 and 2004. Int J Cancer 2008;122(1):165-169. https://doi.org/10.1002/ ijc. 23007

28. Mouw T, Koster A, Wright ME, et al. Education and risk of cancer in a large cohort of men and women in the United States. PLoS One 2008;3(11):e3639. https://doi.org/10.1371/journal.pone.0003639

29. Ogundiran TO, Huo D, Adenipekun A, et al. Case-control study of body size and breast cancer risk in Nigerian women. Am J Epidemiol 2010;172(6):682-690. https://doi.org/10.1093/aje/kwq180

30. Ozmen V, Ozcinar B, Karanlik H, et al. Breast cancer risk factors in Turkish women - a University Hospital based nested case control study. World J Surg Oncol 2009;7:37. https://doi.org/10.1186/1477-7819-7-37

31. Terret C, Castel-Kremer E, Albrand G, Droz JP. Effects of comorbidity on screening and early 1. Terret C, Castel-Kremer E, Albrand G, Droz JP. Effects of comorbidity on screening and early
diagnosis of cancer in elderly people. Lancet Oncol 2009;10(1):80-87. https://doi.org/10.1016/S14702045(08)70336-X

32. Fleming ST, Pursley HG, Newman B, Pavlov D, Chen K. Comorbidity as a predictor of stage of illness for patients with breast cancer. Med Care 2005:43(2):132-140. https://doi.org/10.1016/S14702045(08)70336-X

33. Klabunde CN, Legler JM, Warren JL, Baldwin L-M, Schrag D. A refined comorbidity measurement algorithm for claims-based studies of breast, prostate, colorectal, and lung cancer patients. Ann Epidemiol 2007;17(8):584-590. https://doi.org/10.1016/j.annepidem.2007.03.011

34. Satariano WA, Ragland DR. The effect of comorbidity on 3-year survival of women with primary breas cancer. Ann Intern Med 1994;120(2):104-110. https://doi.org/10.7326/0003-4819-120-2-199401150-00002

35. Houterman S, Janssen-Heijnen M, Verheij C, et al. Comorbidity has negligible impact on treatment and complications but influences survival in breast cancer patients. Br J Cancer 2004;90(12):23322337. https://doi.org/10.1038/sj.bjc.6601844

36. Nagel G, Wedding U, Hoyer H, Röhrig B, Katenkamp D. The impact of comorbidity on the survival of postmenopausal women with breast cancer. J Cancer Res Clin Oncol 2004;130(11):664-670. https:// doi.org/10.1007/s00432-004-0594-3

37. Yancik R, Wesley MN, Ries LA, Havlik RJ, Edwards BK, Yates JW. Effect of age and comorbidity in postmenopausal breast cancer patients aged 55 years and older. JAMA 2001;285(7):885-892. https:// postmenopausal breast cancer $\mathrm{p}$
doi.org/10.1001/jama.285.7.885

38. Shisana O, Labadarios D, Rehle T, et al. The South African National Health and Nutrition Examination Shisana O, Labadarios D, Rehle T, et al. The South African National Health and Nutrition Examination
Survey, 2012: SANHANES-1: The Health and Nutritional Status of the Nation. 2014 edition. Cape Town: HSRC Press, 2014. http://www.hsrc.ac.za/en/research-data/view/6493 (accessed 14 May 2018).
9. Bhana A, Rathod SD, Selohilwe O, Kathree T, Petersen I. The validity of the Patient Health 39. Bhana A, Rathod SD, Selohilwe O, Kathree T, Petersen I. The validity of the Patient Health
Questionnaire for screening depression in chronic care patients in primary health care in South Africa. BMC Psychiatry 2015;15(1):118. https://doi.org/10.1186/s12888-015-0503-0
40. Cholera R, Gaynes B, Pence B, et al. Validity of the Patient Health Questionnaire-9 to screen for depression in a high-HIV burden primary healthcare clinic in Johannesburg, South Africa. J Affect Disord 2014;167:160-166. https://doi.org/10.1016/j.jad.2014.06.003

41. Familiar I, Ortiz-Panozo E, Hall B, et al. Factor structure of the Spanish version of the Patient Health Questionnaire-9 in Mexican women. Int J Methods Psychiatr Res 2015;24(1):74-82. https://doi. org/10.1002/mpr.1461

42. Goff DC, Lloyd-Jones DM, Bennett G, et al. 2013 ACC/AHA guideline on the assessment of cardiovascular risk: A report of the American College of Cardiology/American Heart Association Task Force on Practice Guidelines. J Am Coll Cardiol 2014;63(25 Pt B):2935-2959. https://doi.org/10.1016/j. jacc.2013.11.005

43. World Health Organization. Obesity: Preventing and Managing the Global Epidemic (WHO Technical Report Series 894). Geneva: WHO, 2000. http://www.who.int/nutrition/publications/obesity/WHO_ TRS_894/en/ (accessed 14 May 2018).

44. Klug E, Raal F, Marais A, et al. South African Dyslipidaemia Guideline Consensus Statement. S Afr Med J 2012;102(3):178-187. https://doi.org/10.7196/SAMJ.5502

45. Rao SS, Disraeli P, McGregor T. Impaired glucose tolerance and impaired fasting glucose. Am Fam Physician 2004;69(8):1961-1968.

46. Chobanian AV, Bakris GL, Black HR, et al. Seventh report of the Joint National Committee on Prevention, Detection, Evaluation, and Treatment of High Blood Pressure. Hypertension 2003:42(6):1206-1252. https://doi.org/10.1161/01.HYP.0000107251.49515.c2

47. Dickens C, Joffe M, Jacobson J, et al. Stage at breast cancer diagnosis and distance from diagnostic hospital in a periurban setting: A South African public hospital case series of over 1,000 women. Int J Cancer 2014;135(9):2173-2182. https://doi.org/10.1002/ijc.2886

48. Gaziano TA, Abrahams-Gessel S, Gomez-Olive FX, et al. Cardiometabolic risk in a population of older adults with multiple co-morbidities in rural South Africa: The HAALSI (Health and Aging in Africa: Longitudinal studies of INDEPTH communities) study. BMC Public Health 2017;17(1):206. https:// doi.org/10.1186/s12889-017-4117-y

49. Heerden A, Barnabas RV, Norris SA, Micklesfield LK, Rooyen H, Celum C. High prevalence of HIV and non-communicable disease (NCD) risk factors in rural KwaZulu-Natal, South Africa. J Int AIDS Soc 2017;20(2):e25012. https://doi.org/10.1002/jia2.25012

50. Sheean P, Liang H, Schiffer L, Arroyo C, Stolley M. Examining the prevalence of metabolic syndrome among overweight/obese African-American breast cancer survivors vs. matched non-cancer controls. J Cancer Surviv 2017;11(1):102-110. https://doi.org/10.1007/s11764-016-0566-Z

51. Khakbazan Z, Taghipour A, Latifnejad Roudsari R, Mohammadi E. Help seeking behavior of women with self discovered breast cancer symptoms. A meta-ethnographic synthesis of patient delay. PLoS One 2014:9(12):el10262, https://doi.org/10.1371/journal pone.0110262

52. Ameh S, Klipstein-Grobusch K, d'Ambruoso L, Kahn K, Tollman SM, Gómez-Olivé FX. Quality of integrated chronic disease care in rural South Africa: User and provider perspectives. Health Policy Plan 2017;32(2):257-266. https://doi.org/10.1093/heapol/czw118

53. Boyd CM, Darer J, Boult C, Fried LP, Boult L, Wu AW. Clinical practice guidelines and quality of care for older patients with multiple comorbid diseases: Implications for pay for performance. JAMA 2005;294(6):716-724. https://doi.org/10.1001/jama.294.6.716

54. US Department of Health and Human Services. Multiple Chronic Conditions - a Strategic Framework: Optimum Health and Quality of Life for Individuals with Multiple Chronic Conditions. Washington, DC: HHS, 2010. https://www.hhs.gov/sites/default/files/ash/initiatives/mcc/mcc_framework.pdf (accessed 10 June 2018)

55. Walsh J, Harrison JD, Young JM, Butow PN, Solomon MJ, Masya L. What are the current barriers to effective cancer care coordination? A qualitative study. BMC Health Serv Res 2010;10(1):132. https:// doi.org/10.1186/1472-6963-10-132

56. Fu MR, Axelrod D, Guth AA, et al. Comorbidities and quality of life among breast cancer survivors: A prospective study. J Pers Med 2015;5(3):229-242. https://doi.org/10.3390/jpm5030229

57. Giordano SH, Duan Z, Kuo Y-F, Hortobagyi GN, Goodwin IS. Use and outcomes of adjuvant chemotherapy in older women with breast cancer. J Clin Oncol 2006;24(18):2750-2756. https://doi. $\mathrm{org} / 10.1200 / \mathrm{JCO} .2005 .02 .3028$

58. Gold HT, Do HT, Dick AW. Correlates and effect of suboptimal radiotherapy in women with ductal carcinoma in situ or early invasive breast cancer. Cancer 2008;113(11):3108-3115. https://doi. org/10.1002/cncr.23923

59. Ranganathan P, Pramesh CS, Buyse M. Common pitfalls in statistical analysis: The perils of multiple testing. Perspect Clin Res 2016;7(2):106-107. https://doi.org/10.4103/2229-3485.179436

Accepted 29 August 2018. 